\title{
BMJ Open Getting the right balance? A mixed logit analysis of the relationship between UK training doctors' characteristics and their specialties using the 2013 National Training Survey
}

Idaira Rodriguez Santana, Martin Chalkley

To cite: Rodriguez Santana I, Chalkley M. Getting the right balance? A mixed logit analysis of the relationship between UK training doctors' characteristics and their specialties using the 2013 National Training Survey. BMJ Open 2017;7:e015219. doi:10.1136/ bmjopen-2016-015219

- Prepublication history for this paper is available online. To view these files please visit the journal online (http://dx.doi org/10.1136/bmjopen-2016015219).

Received 5 December 2016 Revised 30 May 2017 Accepted 16 June 2017

CrossMark

Centre for Health Economics, University of York, York, UK

Correspondence to Idaira Rodriguez Santana; idaira.rodriguezsantana@york. ac.uk

\section{ABSTRACT}

Objective To analyse how training doctors' demographic and socioeconomic characteristics vary according to the specialty that they are training for.

Design Descriptive statistics and mixed logistic regression analysis of cross-sectional survey data to quantify evidence of systematic relationships between doctors' characteristics and their specialty.

Setting Doctors in training in the United Kingdom in 2013. Participants 27530 doctors in training but not in their foundation year who responded to the National Training Survey 2013.

Main outcome measures Mixed logit regression estimates and the corresponding odds ratios (calculated separately for all doctors in training and a subsample comprising those educated in the UK), relating gender, age, ethnicity, place of studies, socioeconomic background and parental education to the probability of training for a particular specialty.

Results Being female and being white British increase the chances of being in general practice with respect to any other specialty, while coming from a better-off socioeconomic background and having parents with tertiary education have the opposite effect. Mixed results are found for age and place of studies. For example, the difference between men and women is greatest for surgical specialties for which a man is 12.121 times more likely to be training to a surgical specialty (relative to general practice) than a woman ( $p$-value $<0.01)$. Doctors who attended an independent school which is proxy for doctor's socioeconomic background are 1.789 and 1.413 times more likely to be training for surgical or medical specialties (relative to general practice) than those who attended a state school ( $p$-value $<0.01)$.

Conclusions There are systematic and substantial differences between specialties in respect of training doctors' gender, ethnicity, age and socioeconomic background. The persistent underrepresentation in some specialties of women, minority ethnic groups and of those coming from disadvantaged backgrounds will impact on the representativeness of the profession into the future. Further research is needed to understand how the processes of selection and the self-selection of applicants into specialties gives rise to these observed differences.
Strengths and limitations of this study

- Results are derived from a comprehensive survey with a $97.7 \%$ response rate and account for the role of doctors' socioeconomic background in the specialty allocation process.

- Multinomial mixed logistic regression accounts for multiple covariates to be correlated and to control for doctors' unobserved heterogeneity.

- Access to data was limited by confidentiality requirements of the data sharing agreement.

- The survey data used omits some potentially important control variables such as medical school attended and academic performance of training doctors.

- Only outcomes of a complex specialty allocation process involving application, selection and acceptance are observed, not the process itself.

\section{INTRODUCTION}

Becoming a medical practitioner in the UK is a competitive process and represents a substantial investment of time and financial resources, much of that funded out of taxation. The outcome determines the composition of the medical profession. There is growing concern that the profession should reflect not only appropriate skills but a balance of socioeconomic background, gender and ethnicity ${ }^{1}$ to be representative of the society the doctors serve. Achieving a greater balance could improve patient outcomes $^{2}$ and foster public health policies targeted at deprived and minority groups. ${ }^{3}$

Evidence has been accumulating regarding imbalance in one or other of gender, ethnicity and socioeconomic background across specialties. For example, despite the increase in the number of women entering the medical profession in the last three decades, ${ }^{4}$ there exists a large gender difference in the 
distribution of doctors across specialties ${ }^{4-8}$ and as a result, women now predominate in paediatrics, obstetrics or general practice but are a minority in surgery or radiology.

While there is no direct evidence regarding the distributions of ethnicity and socioeconomic background across specialties in the UK, studies ${ }^{910}$ have shown that applicants from disadvantaged and/or from non-white ethnic backgrounds have less probability of receiving offers from some medical schools, which is an important determinant of specialty allocation. ${ }^{11}$ There is also evidence that national and overseas educated doctors have different application patterns ${ }^{12}$ and that overseas educated doctors have restricted access ${ }^{13}$ to the most popular specialty training posts. This restriction may create an underclass within the NHS. ${ }^{1415}$

There is thus a patchwork of evidence indicating that specialties may be unbalanced in regard to the gender, ethnicity and socioeconomic background of their constituent doctors but no overall view of how these imbalances relate to each other. A fundamental problem is that characteristics such as gender and ethnicity may be correlated so that an apparent gender imbalance can in part or in whole be accounted for by an ethnicity imbalance or vice versa.

We analyse data from the 2013 National Training Survey to examine the distribution of doctors across specialties along with their gender, ethnicity and socioeconomic background. We consider whether there are imbalances in regard to any one of the demographic or socioeconomic covariates, holding the other characteristics constant, by means of a mixed logistic regression model. Our study provides an evidence base for stimulating debate and discussion regarding the possible need to intervene in doctors' training in the UK to redress these imbalances across specialties. A better understanding of how individuals are assigned to specialties is a necessary precondition for the formulation of effective strategies to ensure greater representativeness across medical specialties. With the increasing role of women in the medical workforce, the larger dependence of the UK on overseas educated doctors and the desire to widen access to those coming from deprived backgrounds, the need for that knowledge is urgent.

\section{DATA AND METHODS}

\section{Data and variables}

The General Medical Council (GMC) National Training Survey (NTS) is a cross-sectional survey carried out each year. From 2013 it included questions about doctors' socioeconomic background. ${ }^{16}$ The survey has a high response rate, $97.7 \%$ for 2013 , which translates to a total of 52797 responding individuals out of 54055 who were eligible. ${ }^{17}$ Due to the commitment to confidentiality by the GMC, our study is restricted to individuals who are not unique in respect of the combination of their characteristics and is focused on 40889 doctors. To establish whether there is probable bias from the omission of some individuals we compared the descriptive statistics for the main demographic and socioeconomic characteristics of the complete survey ${ }^{16}{ }^{17}$ and our sample, finding that differences between our sample and population mean values are all smaller than three percentage points. The 13359 doctors carrying out foundation training were excluded from the analysis since they had not selected their specialty, resulting in 27530 doctors in the analysis sample. These were divided into two groups for analysis: a general sample containing all doctors in specialty training and a UK sample composed of 18588 who attended both secondary and university education in the UK.

For each individual there is information on their demographic and socioeconomic characteristics which we encoded as categorical or binary dummy variables: variable man was assigned the value one if the doctor is a man; BME has the value one for black and minority ethnic doctors; age was given in four bands, <30, 30-39, 40-49 and $50+$, which we merged into two groups and defined the variable mature to take the value one if the individual is 40 years old or older and variable UK University is equal to one if a doctor completed their secondary and medical undergraduate studies in the UK. For UK graduates, there is additional information concerning parental education and socioeconomic proxies. The variable parent uni takes the value one if at least one parent has tertiary education. The variables state, grammar and independent take the value one according to the type of secondary school attended. State school is the omitted category in the multivariate analysis. Following previous analyses ${ }^{18}$ school type is used as a proxy for socioeconomic background. In the United Kingdom approximately $7 \%$ of pupils attend independent schools, of which only $1 \%$ receive means-tested scholarships. Finally, the variable income sup is assign the value one if the doctor's household received income support at any point in their childhood.

Each doctor could be assigned to one of 13 categories of training according to their specialisation. We reduced this categorisation to six specialties to group options that have the same core training or that can be regarded as close substitutes. ${ }^{19}$ The resulting specialties analysed are:

1. acute care, emergency medicine and anaesthetics (ACEM);

2. general practice (GP);

3. surgical (SUR);

4. hospital-based specialties including medical specialties, paediatrics and childcare, medical-surgical specialties (ie, obstetrics and gynaecology and ophthalmology), and occupational medicine (HBS);

5. psychiatry (PSY);

6. others including pathology, radiology and public health $(\mathrm{OTH})$.

\section{Methodology}

The specialties associated with doctors in NTS 2013 describe the outcome of the allocation of a doctor to a training post. We only observe the result of a complex 
selection process involving application, selection and acceptance, not the process itself, but seek to examine whether the process operates so as to sort doctors according to their demographic or socioeconomic characteristics. To establish evidence of systematic relationships between doctors' characteristics and specialty allocation in the presence of correlation between these characteristic we estimate individual-level multivariate analysis, by means of mixed logit regression. ${ }^{20}{ }^{21}$ Since specialties as defined are mutually exclusive categories a multinomial logit approach gives a natural means of establishing the effect of an individual's characteristics on the probability of observing them in one specialty, conditional on fixing their other characteristics. A mixed model permitted us to relax some of the strong distributional assumptions implied by a fixed coefficient approach and allows for the estimation of a multinomial logit model with unobserved heterogeneity. ${ }^{21}$ We capture the heterogeneity by allowing the constant term in the model to vary across individuals following a normal distribution and allowing the estimates from the different alternatives to be correlated. Moreover, since covariates with missing observations account for $0.5 \%$ and $5.7 \%$ of our general and $U K$ sample respectively, we proceeded as if data were missing completely at random (MCAR) and based our analysis on a sample of complete observations.

\section{RESULTS}

\section{Descriptive statistics}

Tables 1 and 2 show the distributions of individuals' characteristics by specialty for the general sample and the UK sample respectively. If the allocation process is unaffected by demographic and socioeconomic characteristics we would expect a similar distribution of characteristics in every specialty since in that case each specialty would appear as a random sample from the overall population of doctors in training. The figures show a different picture.

In terms of gender, $45.49 \%$ of the total sample consists of men but in surgical specialties men make up $78.38 \%$ of the total while in general practice they constitute $30.72 \%$. In terms of ethnicity, the greatest deviations from the overall percentage of BME doctors (41.05\%) are observed for ACEM (22.85\%) and for PSY (56.21\%). Similar differences emerge when comparing UK-educated and overseas educated doctors. For example, the largest number of overseas students is observed in psychiatry $(54.19 \%)$ and the smallest in ACEM $(18.25 \%)$ and SUR $(24.7 \%)$ respectively. Table 2 concerns the UK sample and there is additional information on socioeconomic variables. Overall, doctors have attended an independent school in a larger proportion $(35.31 \%)$ than the general UK population. There is again an uneven distribution across specialties; SUR being the group with the largest representation (42.19\%) and GP the smallest (29.93\%). We observe the opposite for state school with the largest representation in GP $(44.57 \%)$ and the smallest from SUR doctors $(32.43 \%)$. Other socioeconomic characteristics present in the data are parental education and income support. The means across all doctors are $65.83 \%$ and $10.23 \%$ respectively. For these variables, there is relatively little variability across specialties.

\section{Regression results}

In the regression tables we report the maximum likelihood coefficient estimates (MLE), its associated z-score, the implied odds ratio (OR) and the associated 95\% confidence interval $(95 \% \mathrm{CI})$. We set GP as the omitted category; it is the single largest category and recurrent problems in recruitment to GP make it a relevant object of comparison. Individual characteristics are captured by the dummy variables described in the section 'Data and variables'.

Table 3 shows the results for all doctors in training. In terms of gender, we observe a positive significant effect of the variable man for all of the alternative specialties to GP, confirming the relationships observed in the descriptive statistics. The greatest effect is associated with SUR for which male doctors are 12.121 times more likely to be allocated in a surgical specialty relative to the GP option. The variable BME has a negative coefficient estimate for all the categories with respect to the base outcome. In this case, the greatest effect is found in the ACEM category, with an OR of 0.289. The regression estimates for the variable mature also coincide with the results observed in the descriptive statistics. The greatest positive significant effect was found for PSYwith an OR of 2.918. The rest of the categories have negative coefficients and ORs less than one, implying for example that being 40 years old or older reduces the probability of being based in any of these specialties relative to GP. Finally, the variable UK university indicates a positive significant effect for the surgical specialties such that a UK-educated doctor is 2.072 times more likely to appear in this specialty with respect to GP. The greatest negative effect is found for PSY with an OR of 0.209 .

Table 4 shows the results for the UK-educated doctors; those who completed both secondary school education and undergraduate studies in the UK. The estimated coefficients and ORs for the variables man, BME and mature are of the same signs and of similar magnitudes to those shown in table 3. In respect of schooling variables (state school is omitted category), which were used to proxy socioeconomic background, we observe positive and significant estimates and ORs greater than one for all specialties with respect to GP. The largest effect is found for surgical specialties for which doctors who attended an independent school are 1.789 times more likely to be in surgical specialties than those who attended a state school relative to GP. The smallest positive effect is associated to PSY with an associated OR of 1.301. Overall, having attended an independent or grammar school reduces the probability of GP with respect to any other specialty. Finally, the estimates for parental education are positive but modest compared with the schooling estimates. Here the greatest effect in magnitude is related to HBS and 


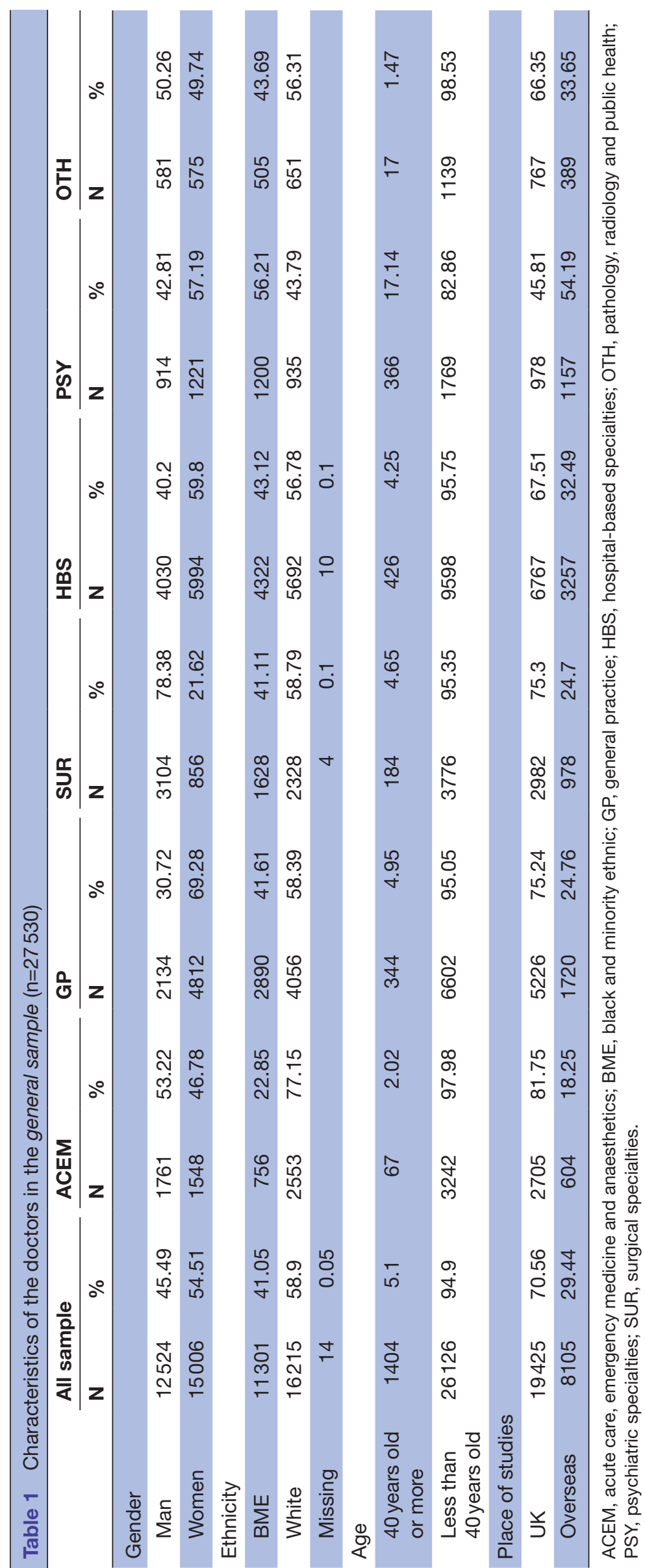




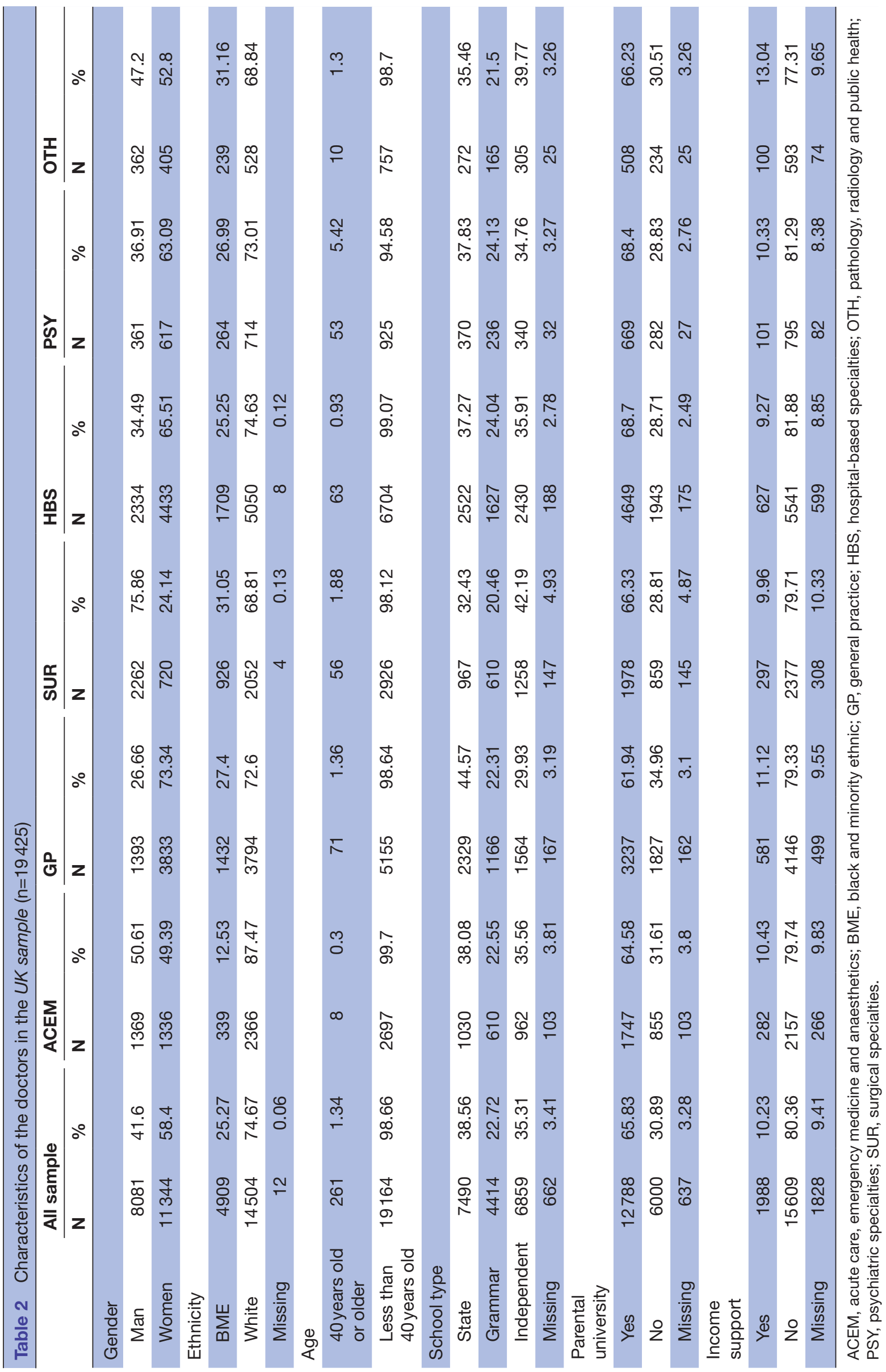




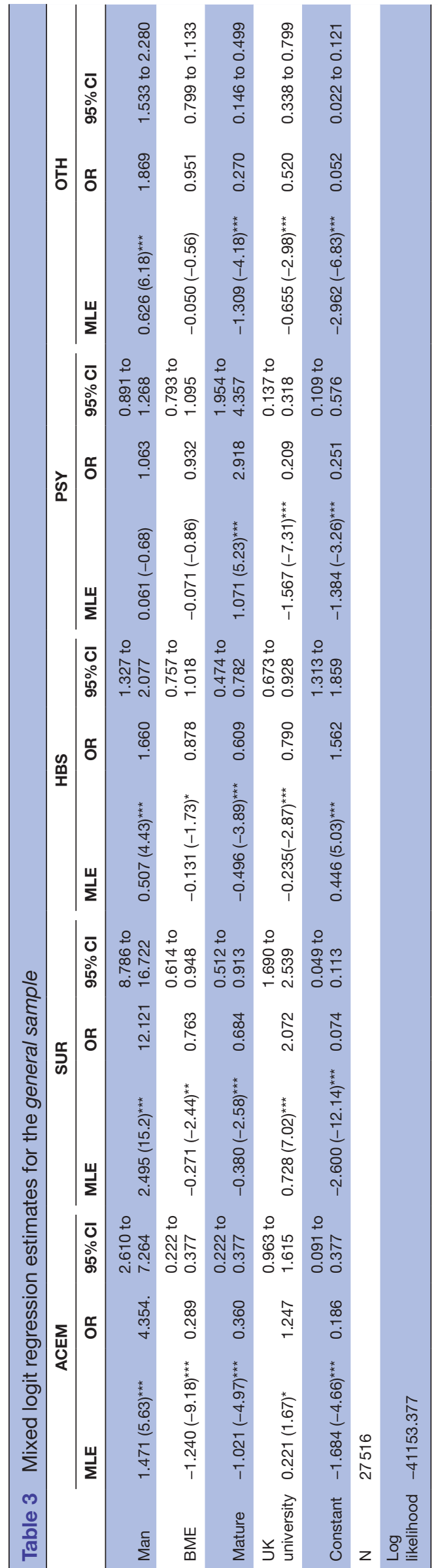

PSY, with associated ORs of 1.311 and 1.321 respectively. To achieve a parsimonious model, we excluded the variable income sup as we did not find statistically significant estimates of its effect in any of the specifications we tested.

\section{DISCUSSION}

Our analysis shows that in respect of socioeconomic and demographic characteristics there are substantial differences across specialties. All of the characteristics we considered constitute potentially important indicators of the representativeness of the medical profession and specialties perform very differently. Our analysis confirmed that the well $\mathrm{known}^{5-8}$ gender gap in some specialties is also present in the cohort of training doctors in 2013. The gap is greatest between GP and SUR . Overall, surgical specialties are more male, white British and socioeconomically privileged than GP. Surgical specialties are typically highly competitive and the mean income for surgical specialties is above the $75 \%$ percentile of the distribution. ${ }^{22}$

In regard to schooling variables our results are new and statistically significant. They imply that doctors from better-off socioeconomic backgrounds are less likely to be based in GP than in any other specialty. In contrast to previous work in this area, we have been able to examine imbalances in both demographic and socioeconomic characteristics simultaneously using a survey that contains rich information on individuals and that has a very high response rate. These data are amenable to robust statistical methods to control for correlation between variables and allow for unobserved heterogeneity. Our results are both novel and more comprehensive than has previously been possible, however they are necessarily specific to the particular selection of doctors studied. Nevertheless, the observed distribution of doctors corresponds to historical trends and the characteristics associated with the different specialties.

As with any survey there are missing data and our study is further limited by confidentiality requirements that reduced the sample we were able to analyse. Since covariates with missing observations only account for $0.5 \%$ and $5.7 \%$ of our general and UK samples respectively, we proceeded as if data were missing completely at random (MCAR) and based our analysis on a sample of complete observations. Comparing our sample to the full survey population did not reveal any differences more than three percentage points in the means of the variables of interest. Nevertheless, there is always a possibility that our sample is biased in ways that cannot be detected by simple comparison of means. For future work on this survey it may be possible to work within the context of a 'safe' environment that would permit sharing of the complete dataset. A further limitation is that there are characteristics of individuals that are relevant to understanding their specialty allocation that are not reported in this survey. In particular, the educational background of doctors in training in respect of the medical school they 


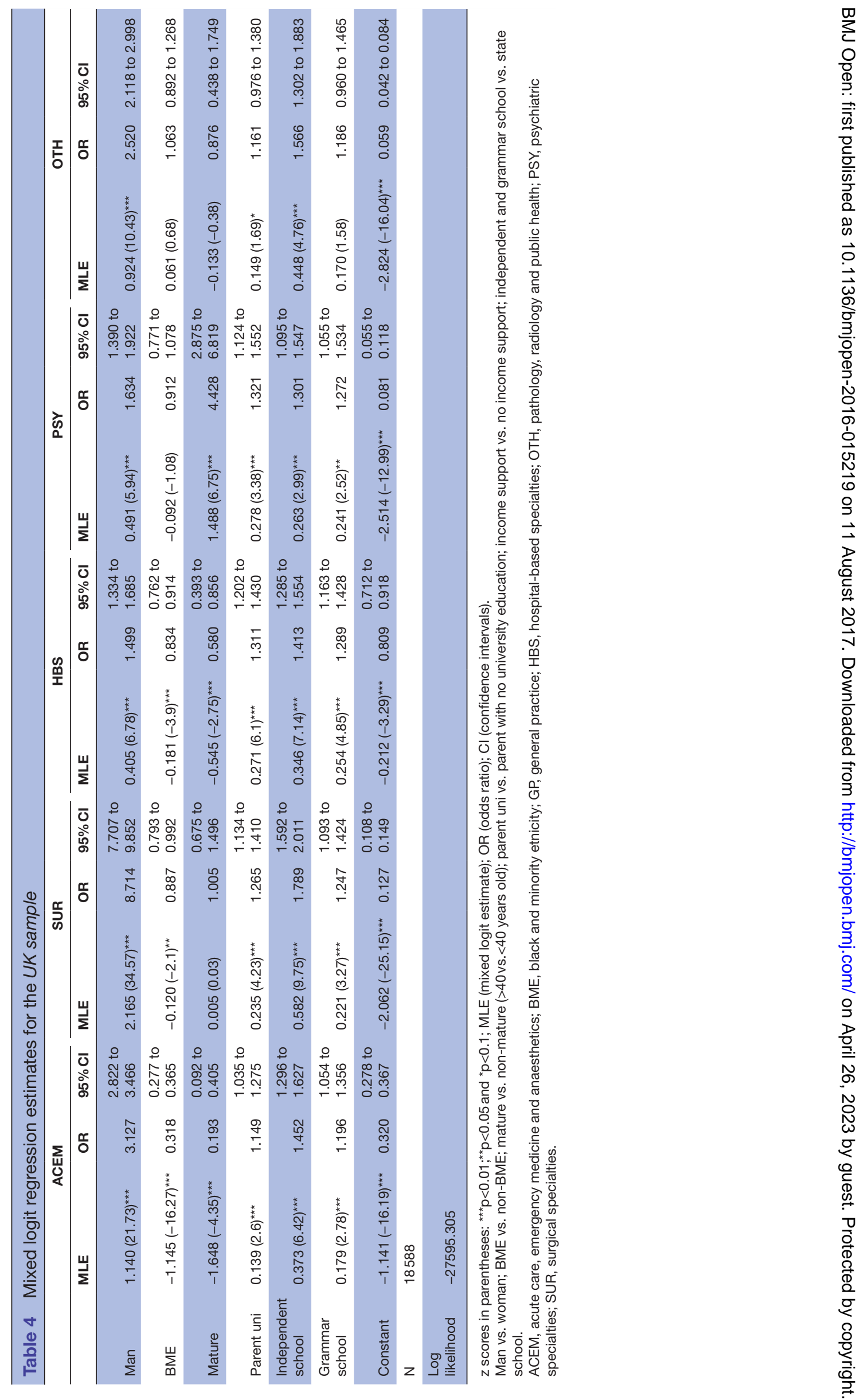


attended and their academic records could potentially be confounders of the estimates of demographic and socioeconomic characteristics. Future work to address this limitation might include linking individual survey responses to administratively recorded data.

Our results can be viewed describing the outcome of a complex process of specialty allocation in which doctors apply, are selected and subsequently choose from the offers that are made to them. We have established that the outcome of this process is highly unbalanced and that some specialties exhibit a dearth of doctors with some characteristics. There are many potential causes for such an imbalance. It might be the result of differences in preferences between socioeconomic groups in terms of characteristics of the specialties, potential earnings and other non-pecuniary benefits of the alternatives and those differences might also have foundations in the secondary school, or as previous literature suggests ${ }^{11}$ in the medical school attended. Alternatively, another determinant of the observed differences between socioeconomic and different gender groups might be due to the existence of some form of statistical discrimination. ${ }^{23}$ The latter is a theory of inequality between groups that is based on stereotypes that do not arise from prejudice or racial and gender bias. For example, doctors might self-select themselves into the less competitive training posts, by actively not applying ${ }^{624}$ or by not investing in the necessary skills to be an admissible candidate because they perceive that the chances of success are low. This then becomes a self-fulfilling prophecy.

Identifying the causes of the imbalances we have documented has considerable importance for policymakers who are concerned to redress them. Medical education is costly and in the UK relies on a substantial injection of public funds. It is therefore natural that policymakers will be concerned that the outcome of medical education reflects societal values and a key task for future research is to find the means of discriminating between the competing explanations. Therein lies the means to intervene successfully. Our research also highlights another potential cause for concern. Approximately $30 \%$ of doctors in the training scheme are educated overseas and they are very unequally distributed over specialties. From an international perspective importing doctors from low-income countries might be seen as a brain drain and in conflict with what has been termed 'ethical recruitment". ${ }^{25}$ Additionally, previous literature ${ }^{14} 15$ has suggested that overseas educated doctors who are allocated to less desirable training positions might be creating an 'underclass' within the NHS. This is a concern for both policymakers and the profession. Future research might usefully focus on the quality of training experience and satisfaction of those overseas doctors.

Acknowledgements We are grateful for comments and suggestions from Karen Bloor, Nigel Rice and Beatriz González López-Valcárcel and those received during presentations at the Health, Econometrics and Data Group Seminar (University of York), the $35^{\text {th }}$ Spanish Health Economics Conference (Granada) and the second Conference on the Economics of the Health Workforce (Milan).
Contributors IRS managed the data and did the statistical analysis. All authors interpreted data and drafted the manuscript. All authors have completed the ICMJE uniform disclosure form at www.icmje.org/coi_disclosure.pdf and declare: no support from any organisation for the submitted work; no financial relationships with any organisations that might have an interest in the submitted work in the previous three years; no other relationships or activities that could appear to have influenced the submitted work.

Funding This research received no specific grant from any funding agency in the public, commercial or not-for-profit sectors.

Competing interests None declared.

Patient consent Not Applicable.

Ethics approval Dr Stephen Holland, chair of University of York's research governance committee approved this study by chair's action because the data are (i) extant (ii) fully anonymised and (iii) non-identifiable. The study raises no other substantive ethical issues.

Provenance and peer review Not commissioned; externally peer reviewed.

Data sharing statement This research has been undertaken using data from the National Training Survey data set available on application from the General Medical Council. We are not permitted to share the raw data with other parties, without the advance written permission of the GMC.

Open Access This is an Open Access article distributed in accordance with the Creative Commons Attribution Non Commercial (CC BY-NC 4.0) license, which permits others to distribute, remix, adapt, build upon this work non-commercially, and license their derivative works on different terms, provided the original work is properly cited and the use is non-commercial. See: http://creativecommons.org/ licenses/by-nc/4.0/

(c) Article author(s) (or their employer(s) unless otherwise stated in the text of the article) 2017. All rights reserved. No commercial use is permitted unless otherwise expressly granted.

\section{REFERENCES}

1. General Medical Council. Generic standars for specialty including GP training. London: General Medical Council, 2010.

2. Tsugawa Y, Jena AB, Figueroa JF, et al. Comparison of hospital mortality and readmission rates for medicare patients Treated by Male vs female physicians. JAMA Intern Med 2017;177:206-13.

3. Cohen JJ, Gabriel BA, Terrell C. The case for diversity in the health care workforce. Health Aff 2002;21:90-102.

4. McKinstry B. Are there too many female medical graduates? yes. BMJ 2008;336:748.

5. McManus IC, Sproston KA. Women in hospital medicine in the United Kingdom: glass ceiling, preference, prejudice or cohort effect? J Epidemiol Community Health 2000;54:10-16.

6. McNally SA. Competition ratios for different specialties and the effect of gender and immigration status. J R Soc Med 2008;101:489-92.

7. Lambert TW, Goldacre MJ, Turner G. Career choices of United Kingdom medical graduates of 2002: questionnaire survey. Med Educ 2006;40:514-21.

8. Goldacre MJ, Laxton L, Lambert TW. Medical graduates' early career choices of specialty and their eventual specialty destinations: UK prospective cohort studies. BMJ 2010;341:c3199.

9. Arulampalam W, Naylor R, Smith J. Doctor who? who gets admission offers in UK medical schools. IZA Discussion Papers 2005. No 1775.

10. McManus IC, Esmail A, Demetriou M. Factors affecting likelihood of applicants being offered a place in medical schools in the United Kingdom in 1996 and 1997: retrospective study commentary: league tables will help_commentary: some legal aspects arising from the study. BMJ 1998;317:1111-7.

11. Goldacre MJ, Turner G, Lambert TW. Variation by medical school in career choices of UK graduates of 1999 and 2000. Med Educ 2004;38:249-58.

12. Fazel S, Ebmeier KP. Specialty choice in UK junior doctors: is psychiatry the least popular specialty for UK and international medical graduates? BMC Med Educ 2009;9:77.

13. British Medical Association. Career and advice support. $2017 \mathrm{http}: / /$ bma.org.uk/.

14. Richards T. The overseas doctors training scheme: failing expectations. BMJ 1994;308:1627-31.

15. Welsh C. Training overseas doctors in the United Kingdom: they must be given accurate information about their job prospects. BMJ 2000;321:253-4. 
16. General Medical Council. National training survey 2013: socioeconomic status questions: General Medical Council. 2013 http://www.gmc-uk.org/education/national_summary_reports.asp (accessed 12 Mar 2017)

17. General Medical Council. National Training Survey 2013: key findings. 2013 http://www.gmc-uk.org/education/national_summary reports.asp (accessed 12 Mar 2017)

18. Milburn A. 2014. Elitist Britain? The Social Mobility and Child Poverty Commission. https://www.gov.uk/government/news/elitist-britainreport-published. (accessed 28 Aug 2014).

19. Health Careers. Explore roles doctors: NHS. 2017 https://www. healthcareers.nhs.uk/EXPLORE-ROLES (accessed 12 Mar 2017)

20. McFadden D, Train K. Mixed MNL models for discrete response. $J$ Appl Econ 2000;15:447-70.
21. Hole AR. Estimating mixed logit models using maximum simulated likelihood. Stata J 2007;7:388-401.

22. Morris S, Elliott B, Ma A, et al. Analysis of consultants' NHS and private incomes in England in 2003/4. JRSM 2008; 101:372-80.

23. Fang $\mathrm{H}$, Moro $\mathrm{A}$. Theories of statistical discrimination and affirmative action: a survey. USA: National Bureau of Economic Research, 2010.

24. Richardson HC, Redfern N. Why do women reject surgical careers? Ann R Coll Surg Engl 2000;82:290-3.

25. Lowell BL, Findlay A. Migration of highly skilled persons from developing countries: impact and policy responses. Int Migr Papers $2001 ; 44$. 